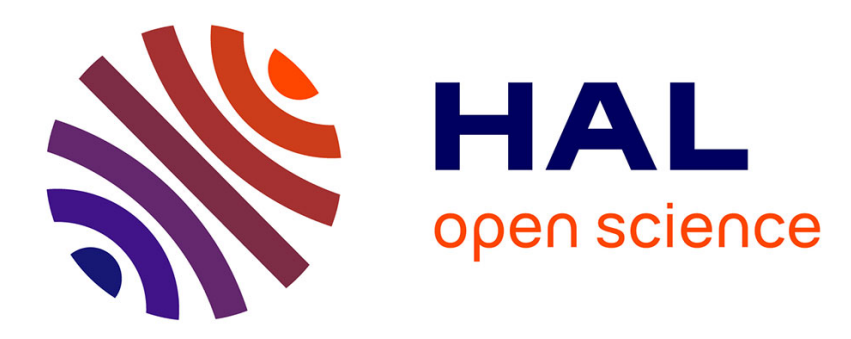

\title{
Disability Insurance and Unemployment Insurance as Substitute Pathways
}

Daniel van Vuuren, Pierre Koning

\section{To cite this version:}

Daniel van Vuuren, Pierre Koning. Disability Insurance and Unemployment Insurance as Substitute Pathways. Applied Economics, 2010, 42 (05), pp.575-588. 10.1080/00036840701704436 . hal00582174

\section{HAL Id: hal-00582174 \\ https://hal.science/hal-00582174}

Submitted on 1 Apr 2011

HAL is a multi-disciplinary open access archive for the deposit and dissemination of scientific research documents, whether they are published or not. The documents may come from teaching and research institutions in France or abroad, or from public or private research centers.
L'archive ouverte pluridisciplinaire HAL, est destinée au dépôt et à la diffusion de documents scientifiques de niveau recherche, publiés ou non, émanant des établissements d'enseignement et de recherche français ou étrangers, des laboratoires publics ou privés. 


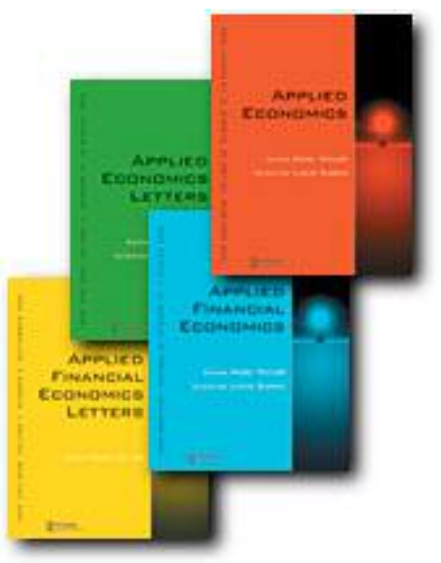

\section{Disability Insurance and Unemployment Insurance as Substitute Pathways}

\begin{tabular}{|c|l|}
\hline Journal: & Applied Economics \\
\hline Manuscript ID: & APE-06-0549 \\
\hline Journal Selection: & Applied Economics \\
\hline JEL Code: & $\begin{array}{l}\text { D21 - Firm Behavior < D2 - Production and Organizations < D - } \\
\text { Microeconomics, H55 - Social Security and Public Pensions }<\text { H5 - } \\
\text { National Government Expenditures and Related Policies }<\text { H }- \text { Public } \\
\text { Disability, etc. }<\text { I1 - Health }<\text { I - Health, Education, and Welfare, } \\
\text { J21 - Labor Force and Employment, Size, and Structure }<\text { J2 - Time } \\
\text { Allocation, Work Behavior, and Employment Determination/Creation } \\
<\text { J - Labor and Demographic Economics }\end{array}$ \\
\hline \hline Keywords: & Firm behaviour, social security, disability, unemployment \\
\hline \hline
\end{tabular}

\section{S) ScholaroNE \\ Manuscript Central}




\title{
Disability Insurance and Unemployment Insurance
} as Substitute Pathways

\author{
Pierre W.C. Koning \\ CPB Netherlands Bureau for Economic Policy Analysis \\ P.O. Box 80510, 2508 GM Den Haag, The Netherlands \\ Daniel J. van Vuuren* \\ CPB Netherlands Bureau for Economic Policy Analysis \\ and Vrije Universiteit Amsterdam (Department of Econometrics) \\ P.O. Box 80510, 2508 GM Den Haag, The Netherlands
}

September 8, 2006

\begin{abstract}
In this paper, we estimate the degree of substitution between enrolment into Disability Insurance (DI) and Unemployment Insurance (UI) in the Netherlands. Starting in the 1990s many policy measures aimed at reducing DI enrolment, and increase labour force participation. We quantify whether these policy measures have led to a reduction in hidden unemployment in DI. A side effect of the reforms may be increased pressure on UI. Therefore, we simultaneously estimate reverse substitution, that is, hidden disability in UI. To this end, we employ a sample of firms in the Dutch AVO database from the period 1993-2002. Using instrumental variables in a bivariate Tobit specification, we identify the hidden components in both respective schemes. The estimation results indicate that about $3 \%$ of all dismissals took place through DI, which implies that about one quarter of the DI enrolments observed in our sample in fact consists of hidden unemployment. We find no evidence for reverse substitution of disabled persons ending up in UI.
\end{abstract}

Keywords: Firm behaviour, social security, disability, employment determination

JEL codes: D21,H55,I12,J2

\footnotetext{
${ }^{*}$ Corresponding author. E-mail: djvv@cpb.nl
} 


\section{Introduction}

In this paper, we address substitution between Unemployment Insurance (UI) and Disability Insurance (DI) in the Netherlands. As in other countries, there has been much debate on this issue both by economists and policymakers. By now, it is widely believed that the Dutch DI scheme has contained much hidden unemployment in the past years, although empirical estimates show quite some divergence, with estimates ranging from 10 to $50 \%$. Yet, it is unclear how the current status has developed after the many reforms of DI initiated by the Dutch government in the 1990s. Indeed, enrolment rates have slipped considerably over the years, from over $1.5 \%$ of the workforce during the early 1990 s until less than $1 \%$ in the early 2000 s. This suggests that the various policy measures taken have been effective, or, to put it in other words, suggesting that hidden unemployment in DI has fallen considerably. There may however be other factors at stake, such as the business cycle, the population composition, etc. Another possible complication is that persons who are in fact eligible to receiving DI benefits are not receiving any as a result of a wrong decision of the medical examiner (erroneous denials, or type I errors). It may also be the case that disabled persons do not even apply for DI benefits as they do not have any confidence in being admitted to the scheme. In this paper, we will first seek to investigate whether hidden unemployment in DI has indeed decreased over the years, and second, we will investigate whether there has been any reverse substitution of disabled persons into the UI scheme.

In the relevant literature, one of the first contributions giving explicit estimates for the degree of hidden unemployment in the Netherlands' DI scheme was Aarts \& de Jong (1992), who used cross-section data from 1980 
to estimate a share of hidden unemployment within DI enrolment of 3351\%. Westerhout (1996) used aggregate data for the period 1973-1992 and confirms that nearly half of the persons receiving DI benefits are in fact unemployed. The most recent study in this sequence of Hassink, van Ours \& Ridder (1997) uses micro data for the period 1988-1990, and finds a percentage of hidden unemployment of 10. Another interesting finding is that a quarter of the employees enrolling into DI are not replaced by new workers, suggesting that these are, in fact, layoffs (Hassink 2000).

For other countries there exists quite some empirical evidence as well. For the United States, both Autor \& Duggan (2003) and Black, Daniel \& Sanders (2002) demonstrate that the U.S. DI scheme contains hidden unemployment. The latter paper uses inter-state variation to show that the recessions of 1991 and 2001 increased pressure on DI. Autor \& Duggan (2003) find that the rising replacement rates for low skilled workers led to a higher incidence of disability. In Canada, the rise of replacement rates in all provinces except Quebec was found to decrease the labour force participation (Gruber 2000). An interesting recent paper by Duggan, Singleton \& Song (2005) considers the effect of the 1983 Social Security ${ }^{1}$ reform on the number of disability recipients in the United States. The authors find that the reduction of Social Security generosity led to increased pressure on Disability Insurance. On the other hand, Riphahn (1997) rejects the hypothesis that DI and UI can be considered as substitutes for German elderly workers.

Our paper adds to this literature in two ways. First, we use a recent administrative data set with employer records on layoffs and disability enrolments. During the 1990s and early 2000s, the Dutch government has almost

\footnotetext{
${ }^{1}$ Social Security is the U.S. public old age pension.
} 
continuously reformed the DI scheme, so that the estimates discussed above may be outdated by now. Second, we are able not only to investigate hidden unemployment in DI, but also the 'reverse substitution effect', i.e. hidden disability in UI. Typically, substitution effects are associated with workers entering DI as an alternative to dismissals. Within the context of our model, however, we allow substitution to exist simultaneously in both directions. As was just mentioned, the reverse substitution effect may have become important, because the various policy measures taken imply an increasing risk of erroneous denials of DI admission.

We will consider a simple model of the firm, which may either dismiss its employees through the UI scheme and/or lose some through the DI scheme, while allowing for substitution between the two schemes (i.e. dismissals through the DI scheme and disabilities through the UI scheme). The identification of the respective effects hinges on the imposition of exclusion restrictions on bivariate Tobit estimates of enrolment rates in the two schemes. In order to identify the hidden components, we impose two sets of exclusion restrictions. Before discussing these, it should be noted that the exclusion restrictions demand that no direct causal relation exists between the variables and the respective enrolment rates. Given the fact that we control both for observed and unobserved firm and worker characteristics we take account of selection effects that may potentially bias our instrumental variables estimates of the DI enrolment and UI enrolment regressions, respectively. Our first exclusion restriction demands that the wage level should exclusively affect UI enrolment but not DI enrolment. On the one hand, it is intuitive that the wage level affects the layoff decision of firms, as wages directly affect the demand for labour. On the other hand, DI enrolment rates should not depend on such a business decision, as disability 
is typically the result of health shocks and does not result (directly) from a change in wages. Thus, if we find that the wage level within firms affects DI enrolment rates this indicates the presence of hidden unemployment in DI. Second, it is assumed that UI enrolment should not be affected by function complexity. Thus, if we find this variable to impact UI enrolment, then we interpret this as hidden disability.

Our empirical findings point out that about $3 \%$ of all dismissals are through the DI scheme, which implies that about one quarter of DI enrolments consists of hidden unemployment. This estimate is however not very precise compared to that in Koning \& van Vuuren (2006), who employ a much larger dataset. For practically the same period, the latter paper however finds nearly the same result with $3 \%$ of all dismissals occurring through the DI scheme. In the second place, no evidence is found for reverse substitution between UI and DI. That is, our estimation results point out that the many reforms taken since the 1990s have not led to increased pressure on the UI scheme.

In section 2, we first discuss some background on the Dutch DI scheme. In section 3 we discuss the data. Section 4 describes the empirical strategy used in this paper. Finally, the estimation results are discussed in section 5 .

\section{Disability Insurance in the Netherlands}

The public Disability Insurance (DI) scheme in the Netherlands was introduced in 1967, and was designed to insure those workers who do not recover from sickness within a year. Any worker is fully insured from the moment of having a paid job, i.e. it is not required that workers have been insured during a certain period of time prior to the moment of application for DI 
benefits (as is the case in most other western countries). A second feature is that any form of disability is insured, whether stemming from professional risk or social risk. A final characteristic worth mentioning is that applicants who lose at least $15 \%$ of their earnings capacity qualify for DI benefits. Workers becoming disabled for $80 \%$ or more receive full benefits, while partially disabled $(15-80 \%)$ receive pro rata benefits ${ }^{2}$

During the 1970s, enrolment rates doubled from an intial $1 \%$ of the labour force to about $2 \%$ by the end of the decade (Figure 1). During that time DI was widely used as an early retirement arrangement for workers who were not able to find a job as a consequence of the international recession. Despite the introduction of 'official' early retirement schemes during the late 1970s / early 1980s ${ }^{3}$ DI enrolment rates remained stable at about $1.5 \%$ until the early 1990s. In the mean time, the number of DI recipients had risen from less than 3 to more than $7 \%$ of the potential workforce (Figure 1). This development obviously put a huge financial burden on the Dutch working population.

As a consequence of this development, many policy measures were taken. An important reform started in 1987, when replacement rates were lowered, and admission to DI benefits was no longer linked to the labour market situation. Before that date, labour market conditions were taken into account in the admission decision, thus in fact facilitating hidden unemployment in the DI scheme. However, this reform did not generate substantial effects, and hence the 1990s saw no less than six subsequent reforms. Starting in

\footnotetext{
${ }^{2}$ Note that benefit levels are laid down in collective labour agreements, so that variation exists over different sectors / firms. Also note that, starting in 2006, the minimum disability percentage in order to qualify for DI benefits has has been raised to 35 .

${ }^{3}$ See, e.g., Euwals, van Vuuren \& Wolthoff (2006) for a discussion, and evaluation of these early retirement schemes.
} 
1993, admission criteria were tightened, and benefit cuts were introduced. The latter measure however proved ineffective, as the social partners decided to collectively 'repair' this by raising higher DI premiums. In 1994, financial incentives for employers were introduced to lower the use of sickness benefits, and hence lower the inflow into DI. Those incentives comprised, amongst others, differentiated employer premiums for sickness insurance. In 1995, part of the 1992 reform was again lifted. The privatisation of sickness insurance in 1996 made employers bear the financial risk of sickness of their personnel. From 1998 on, premiums for DI had to be paid by the employer instead of the employee, and these were differentiated according to DI enrolment history (experience rating). In 1998 it was also made more attractive for employers to hire partially disabled workers.

Finally, since 2002 both employers and employees must prove that they have put enough effort in preventing disability during the preceding period of sickness. If their efforts do not meet requirements, then either the employer may have to pay additional sickness benefits (i.e. the sickness period is extended) or the employee's application for DI benefits may be rejected. This measure is found to be highly effective (de Jong, Lindeboom \& van der Klaauw 2006) 4

Looking at Figure 2 again, it is observed that the DI enrolment rate shows a downward sloping trend from 1992 on. Moreover, the stock of DI recipients stabilised at a rate slightly lower than $7 \%$ of the potential workforce (Figure 1). Enrolment rates were at an all time low during the early 2000s. On the other hand, these were relatively high during the second half of the 1990s. In conclusion, the time pattern since the early 1990s suggests

\footnotetext{
${ }^{4}$ Note that new reforms have taken place in 2004 and 2006, but this is beyond the scope of this paper as our data set ends in 2002 (see section 3).
} 
that the various policy measures just discussed may have had important (negative) effects on the use of DI.

[insert Figure 1 about here]

[insert Figure 2 about here]

\section{Data}

In this paper, we use the AVO data set of the Netherlands' Labour Inspectorate which covers the period 1993-2002 5 The data are based on administrative records of firms by means of a stratified two step sampling procedure. In the first step, a sample of firms is drawn from the Inspectorate's own firm register using a stratified (by industry and firm size) design. The number of strata changes between surveys. Typically, each year's sample contains about 1500-2000 firms drawn from about 100-300 strata. Firms with less than 10 workers are underrepresented, and large firms are overrepresented. This is however not relevant for our analysis, as we aim to describe firm behaviour at the micro-level and the strata selection process can be considered exogenous here $6^{6}$ In the second step, a sample of workers is drawn within each of these firms. From small firms ( $i 20$ employees) the entire workforce was sampled, and for larger firms, the fraction of workers who were sampled decreases with firm size. Thus, the second step of the sampling procedure provides us with extensive information on the workforce composition of firms. In particular, we observe age, gender, education, part-time work, income, function type, and function complexity distribution of the workforce.

\footnotetext{
${ }^{5}$ The acronym 'AVO' stands for 'Research on terms of employment' (in Dutch: 'Arbeids Voorwaarden Onderzoek').

${ }^{6}$ Of course, when aggregate predictions are to be made on the basis of our empirical analysis the stratified sampling scheme should be taken into account, e.g. by weighting the observations.
} 
Furthermore, we observe the number of enrolments in both Disability Insurance (DI) and Unemployment Insurance (UI) from the sampled workers. Two important advantages of the AVO data are that we observe both worker and firm characteristics, and that it is based on administrative records so that we have only few missing observations.

The full dataset has 20,958 firm-year observations, of which one third was omitted because the collective labour agreement code was not available. We will need this last variable in order to take account of unobserved heterogeneity (see section 4). Furthermore, we have omitted a further 3,602 observations (17\%) for which the data were incomplete. Thus, the resulting dataset contains 10,437 obervations. Table 1 shows some characteristics of the AVO data set. We see that the average firm has $3.4 \%$ of its personnel enrolled into UI, and $0.4 \%$ into DI. These figures are expressed on a yearly basis, as each observation in our data set concerns a firm-year observation. It is striking that most firms in the sample either face positive DI enrolment or positive UI enrolment, but that the combination of the two is almost absent. We also calculated correlation coefficients between the two enrolment rates. It is unclear a priori whether substitution between the two schemes should result in a positive or a negative correlation coefficient. If, for example, the economy is in a recession, and firing rates are high, then substitution may imply positive correlation between both enrolment rates. However, if we condition on the business cycle, then it is more likely that substitution implies negative correlation. The reason is that in case of a fixed state of the business cycle, the desired fraction of workers to be laid off is more or less fixed, and therefore, substitution implies that a rise in the use of one scheme will come together with a decline in the other. Table 1 indeed shows that the correlation coefficient is negative in 7 out of 8 years, 
suggesting that substitution might play a role. Of course, these are only indications, and a formal proof is yet to be given.

Furthermore, Table 1 shows sample statistics concerning the workforce composition, firm size, and year. From these figures it becomes apparent that there exists much variation in exogenous variables among the different firm-year observations, which will obviously be of great help in identifying the key parameters of interest in this paper. This is particularly the case for the variables concerning income and function complexity, as these will be used to identify the shares of hidden unemployment and hidden disability in DI and UI, respectively (in the next two sections we will elaborate further on this crucial point). The observations are evenly distributed over the different years, although no data were availabe for the years 1996 and 1999.

[insert Table 1 about here]

\section{Empirical strategy}

The empirical strategy employed in this paper is a generalisation of Hassink et al. (1997) and Koning \& van Vuuren (2006). In the first stage we estimate a bivariate Tobit model, and in the second stage the underlying structural parameters are recovered through minimum distance estimation. While Koning and van Vuuren only focus on hidden unemployment in Disability Insurance (DI), we will also seek to identify the level of hidden disability in Unemployment Insurance (UI). First, we discuss the model, then we translate this into an empirical model in subsection 4.2, and finally we will explain the estimation procedure more precisely in subsection 4.3 . 


\subsection{The model}

Firms may experience incentives to dismiss employees through the DI scheme instead of the UI scheme. For instance, making use of the unemployment scheme may involve quite some procedural efforts, while the application for DI benefits may be demanding less time for the employer. Also, financial motives may play a role. While disability is not perfectly verifiable, the DI scheme may thus be an attractive alternative to the UI scheme. On the other hand, the many reforms of the DI scheme (see section 2) may have led to reverse substitution, that is, disabled workers ending up in the UI scheme. A possible reason is that disabled workers are not easily awarded DI benefits, so that the UI scheme may be a convenient alternative.

Let us now formalise substitution between the two schemes in a simple behavioural model for the firm. Firms have a desired dismissal rate $f^{0}$ and a 'true' disability rate $d^{0}$. Spillovers between the DI scheme and the UI scheme are characterised by $\lambda(\lambda \geq 0)$ and $\mu(\mu \geq 0)$, where the parameter $\lambda$ represents the fraction of desired layoffs that is directed to the disability scheme, and the parameter $\mu$ the fraction of disabled which ends up in the unemployment scheme. Hence, the observed UI and DI enrolment rates equal

$$
\begin{aligned}
& f=(1-\lambda) f^{0}+\mu d^{0} \\
& d=(1-\mu) d^{0}+\lambda f^{0}
\end{aligned}
$$

Clearly, our interest lies in the size of the respective components $\mu d^{0}$ and $\lambda f^{0}$. Dividing these components by the actual enrolment fractions $f$ and $d$ yields the following expressions for the fractions of erroneous admissions 
into UI and DI, respectively:

$$
\begin{aligned}
& s_{1}:=\frac{\mu d^{0}}{f}=\mu^{*} \frac{d}{f}-\lambda^{*} \mu\left(1+\frac{d}{f}\right) \approx \mu \frac{d}{f} \\
& s_{2}:=\frac{\lambda f^{0}}{d}=\lambda^{*} \frac{f}{d}-\mu^{*} \lambda\left(1+\frac{f}{d}\right) \approx \lambda \frac{f}{d}
\end{aligned}
$$

where

$$
\lambda^{*}:=\frac{\lambda}{1-\lambda-\mu} \quad \text { and } \quad \mu^{*}:=\frac{\mu}{1-\lambda-\mu} .
$$

Using the terminology of Aarts \& de Jong (1992) these fractions can also be labelled 'type II errors'. However, these errors may be (partly) canceled out by the opposite effect, namely workers who are wrongfully directed to the other scheme (type I error). If type I error and type II error are of about the same size, then the net amount of substitution between the two schemes will come close to zero. Formally, the net fractions of hidden components in DI and UI write as:

$$
\begin{aligned}
& t_{1}:=1-\frac{f^{0}}{f}=\mu^{*} \frac{d}{f}-\lambda^{*} \approx \mu \frac{d}{f}-\lambda \\
& t_{2}:=1-\frac{d^{0}}{d}=\lambda^{*} \frac{f}{d}-\mu^{*} \approx \lambda \frac{f}{d}-\mu
\end{aligned}
$$

Comparing these equations with (2), it can be seen that the fractions of type I error in UI and DI approximate $\lambda$ and $\mu$, respectively. Note from the above expressions that the net substitution (in percentage points) into a given scheme is precisely the negative of that in the other scheme $\left(t_{2} d=-t_{1} f\right)$, so that either $t_{1}$ or $t_{2}$ is positive while the other has to be negative. 


\subsection{Empirical specification}

Our starting point is the following empirical specification for the firm's desired layoff rate $f^{0}$ and 'true' disability rate $d^{0}$ :

$$
\begin{aligned}
f^{0} & =\beta_{0 f}^{\prime} x_{0}+\beta_{f}^{\prime} x_{f}+u_{f} \\
d^{0} & =\beta_{0 d}^{\prime} x_{0}+\beta_{d}^{\prime} x_{d}+u_{d} \\
u & =\left(\begin{array}{l}
u_{f} \\
u_{d}
\end{array}\right) \sim N(0, \Sigma), \text { with } \Sigma=\left(\begin{array}{cc}
\sigma_{f}^{2} & \rho_{f d} \sigma_{f} \sigma_{d} \\
\rho_{f d} \sigma_{f} \sigma_{d} & \sigma_{d}^{2}
\end{array}\right)
\end{aligned}
$$

It is assumed that the incidence of layoffs and disabilities depends on firm characteristics, worker characteristics, and the state of the economy. However, only the two latter types of variables are contained in the $x$-vectors; the way to control for firm-specific characteristics is addressed in subsection 4.3 . The vector $x_{0}$ contains common covariates, $x_{f}$ is a vector of covariates affecting the desired layoff rate but not the true disability rate, and $x_{d}$ is a vector of covariates affecting the true disability rate but not the desired layoff rate. The slope parameters of our model are organised in the $\beta$-vectors with corresponding underscores. Both $x_{f}$ and $x_{d}$ contain a constant term. We assume normality, and the correlation coefficient $\rho_{f d}$ allows for some 'natural' correlation between $f^{0}$ and $d^{0}$. That is, the layoff and disability rates may be correlated even though this needs not be a sign of substitution between the corresponding schemes.

We may now substitute this empirical specification for $f^{0}$ and $d^{0}$ into (1) to obtain an empirical specification for the observed enrolment rates into UI 
and DI. This yields:

$$
\begin{aligned}
& f=\gamma_{0 f}^{\prime} x_{0}+\gamma_{f f}^{\prime} x_{f}+\gamma_{d f}^{\prime} x_{d}+v_{f} \\
& d=\gamma_{0 d}^{\prime} x_{0}+\gamma_{f d}^{\prime} x_{f}+\gamma_{d d}^{\prime} x_{d}+v_{d} \\
& v=\left(\begin{array}{c}
v_{f} \\
v_{d}
\end{array}\right) \sim N\left(0, \Sigma_{v}\right), \text { with } \Sigma_{v}=\left(\begin{array}{cc}
\tau_{f}^{2} & \rho_{v} \tau_{f} \tau_{d} \\
\rho_{v} \tau_{f} \tau_{d} & \tau_{d}^{2}
\end{array}\right)
\end{aligned}
$$

where

$$
\begin{aligned}
\gamma_{0 f} & =(1-\lambda) \beta_{0 f}+\mu \beta_{0 d} \\
\gamma_{f f} & =(1-\lambda) \beta_{f} \\
\gamma_{d f} & =\mu \beta_{d} \\
\gamma_{0 d} & =(1-\mu) \beta_{0 d}+\lambda \beta_{0 f} \\
\gamma_{f d} & =(1-\mu) \beta_{d} \\
\gamma_{d d} & =\lambda \beta_{f} \\
\tau_{f}^{2} & =(1-\lambda)^{2} \sigma_{f}^{2}+\mu^{2} \sigma_{d}^{2}+2 \mu(1-\lambda) \rho_{f d} \sigma_{f} \sigma_{d} \\
\tau_{d}^{2} & =(1-\mu)^{2} \sigma_{d}^{2}+\lambda^{2} \sigma_{f}^{2}+2 \lambda(1-\mu) \rho_{f d} \sigma_{f} \sigma_{d} \\
\rho_{v} \tau_{f} \tau_{d} & =\lambda(1-\lambda) \sigma_{f}^{2}+\mu(1-\mu) \sigma_{d}^{2}+(1-\lambda-\mu+2 \lambda \mu) \rho_{f d} \sigma_{f} \sigma_{d}
\end{aligned}
$$

Here $\tau_{f}^{2}, \tau_{d}^{2}$ and $\rho_{v}$ represent the variances, and the correlation between $v_{f}$ and $v_{d}$, respectively. It can be seen that for $\lambda$ and $\mu$ close to zero, the correlation coefficient $\rho_{v}$ can be approximated by a first order Taylor series expansion: $\rho_{v} \approx \rho_{f d}+\frac{\sigma_{f}}{\sigma_{d}} \lambda+\frac{\sigma_{d}}{\sigma_{f}} \mu$. This expression makes apparent that the correlation coefficient between $v_{f}$ and $v_{d}$ has three components. The first term relates to the correlation between the error terms in the underlying model ('true' effects), whereas the second and third correspond with the substitution parameters $\lambda$ and $\mu$. Thus, the observed correlation between the 
enrolment fractions into UI and DI can be decomposed into three terms: the first one relating to some 'natural' correlation between unemployment and disability $\left(\rho_{f d}\right)$, and the second and third relating to substitution between both schemes.

We incorporate two refinements into the model specification $(5)$ in order to take account of the fact that smaller firms are likely to witness more variation in their enrolment rates than larger firms. This is simply a consequence of the law of large numbers. The enrolment rate of a firm is identical to the average enrolment rate of the firms' employees, and, while the law of large numbers applies to the latter, the variance of this average decreases at the rate of the size of the firm. Thus, we have a case for heteroscedastic error terms depending on firm size $n$, which is specified as follows:

$$
\begin{aligned}
& \ln \tau_{f}=\alpha_{f}+\eta \ln n \\
& \ln \tau_{d}=\alpha_{d}+\eta \ln n
\end{aligned}
$$

As is well-known, the law of large numbers predicts that $\eta$ should be close to $-\frac{1}{2}$. However, other factors may impact this parameter as well. For instance, if the (unexplained) variation in enrolment rates is larger for large firms than for small firms, then $\eta$ will be closer to zero. If indeed $\eta>-\frac{1}{2}$, this may have two explanations. First, it may imply that larger firms are more heterogeneous than smaller firms (between-firm heterogeneity), and second, it may imply that a given large firm has a relatively fanciful course over time of the concerning enrolment rate (within-firm heterogeneity). An analogous reasoning obviously applies for $\tau_{d}$.

The second refinement deals with the large share of zero observations in our data set (see Table 1). To take account of this we will estimate 
(5) as a Tobit; that is, the error terms $v_{f}$ and $v_{d}$ are (left-) censored at $-\left(\gamma_{0 f}^{\prime} x_{0}+\gamma_{f f}^{\prime} x_{f}+\gamma_{d f}^{\prime} x_{d}\right)$ and $-\left(\gamma_{0 d}^{\prime} x_{0}+\gamma_{f d}^{\prime} x_{f}+\gamma_{d d}^{\prime} x_{d}\right)$, respectively. This will be of particular relevance for smaller firms, which have a higher likelihood of witnessing a zero enrolment rate. Note however that a Tobit version of (5) will improve the model fit for larger firms as well, as these still face a positive probability to observe no enrolment into DI or UI in a given year.

\subsection{Estimation procedure}

Our estimation procedure consists of two steps. In the first step we estimate (5) directly, i.e. without imposing any restrictions on coefficients. This produces maximum likelihood estimates of the parameter vector $\theta_{0}=$ $\left(\gamma_{0 f}, \gamma_{f f}, \gamma_{d f}, \gamma_{0 d}, \gamma_{f d}, \gamma_{d d}, \alpha_{f}, \alpha_{d}, \eta, \rho_{v}\right)$. In the second step we use these reduced form estimates to recover the structural parameters in $\theta=\left(\beta_{0 f}, \beta_{f}\right.$, $\left.\beta_{0 d}, \beta_{d}, \sigma_{f}, \sigma_{d}, \rho_{f} d\right)$ by Minimum Distance estimation.

In the first step, we will exploit the panel dimension of our data and make an attempt to correct for unobserved heterogeneity through the use of Mundlak time-averages (Wooldridge 2002). Because the panel dimension of our data is at the level of collective labour agreements (CLA's) we will only be able to control for unobserved heterogeneity insofar this is at the CLA level. The CLA level is in some instances equivalent to the firm level, but in other instances the CLA concerns more than one firm. However, it is typical that multiple firms being subject to one particular CLA are much alike. A more extensive discussion on this approach to correct for unobserved heterogeneity is found in Koning \& van Vuuren (2006). Introducing time and CLA subscripts $t$ and $i$, respectively, we thus arrive at the following 
model specification:

$$
\begin{aligned}
f_{i t} & =\max \left(0, \gamma_{0 f}^{\prime} x_{0, i t}+\gamma_{f f}^{\prime} x_{f, i t}+\gamma_{d f}^{\prime} x_{d, i t}+c_{f, i}+v_{f, i t}\right) \\
d_{i t} & =\max \left(0, \gamma_{0 d}^{\prime} x_{0, i t}+\gamma_{f d}^{\prime} x_{f, i t}+\gamma_{d d}^{\prime} x_{d, i t}+c_{d, i}+v_{d, i t}\right) \\
v_{i t} & =\left(\begin{array}{c}
v_{f, i t} \\
v_{d, i t}
\end{array}\right) \sim N\left(0, \Sigma_{v}\right), \text { with } \Sigma_{v}=e^{2 \eta J(n)} \cdot\left(\begin{array}{cc}
e^{2 \alpha_{f}} & \rho_{v} e^{\alpha_{f}+\alpha_{d}} \\
\rho_{v} e^{\alpha_{f}+\alpha_{d}} & e^{2 \alpha_{d}}
\end{array}\right)
\end{aligned}
$$

where

$$
\begin{gathered}
c_{f, i}=\delta_{0 f} \bar{x}_{0, i}+\delta_{f f} \bar{x}_{f, i}+\delta_{d f} \bar{x}_{d, i} \\
c_{d, i}=\delta_{0 d} \bar{x}_{0, i}+\delta_{f d} \bar{x}_{f, i}+\delta_{d d} \bar{x}_{d, i}
\end{gathered}
$$

Here $\bar{x}_{,, i}$ denotes the time average value of the vector $x_{,, i}$ for a given collective labour agreement $i$. The log-likelihood equals

$$
\begin{aligned}
\ell\left(\theta_{0}\right) & =\sum_{i, t}\left[\ln \phi_{2}\left(\frac{f_{i t}-\omega_{f, i t}}{\tau_{f}}, \frac{d_{i t}-\omega_{d, i t}}{\tau_{d}}, \rho_{v}\right)\right]^{I_{f, i t} I_{d, i t}} \\
+ & {\left[\ln \Phi\left(\frac{-\frac{\omega_{f, i t}}{\tau_{f}}-\rho_{v} \frac{d_{i t}-\omega_{d, i t}}{\tau_{d}}}{\sqrt{1-\rho_{v}^{2}}}\right)+\ln \phi\left(\frac{d_{i t}-\omega_{d, i t}}{\tau_{d}}\right)-\ln \tau_{d}\right]^{\left(1-I_{f, i t}\right) I_{d, i t}} } \\
+ & {\left[\ln \Phi\left(\frac{-\frac{\omega_{d, i t}}{\tau_{d}}-\rho_{v} \frac{f_{i t}-\omega_{f, i t}}{\tau_{f}}}{\sqrt{1-\rho_{v}^{2}}}\right)+\ln \phi\left(\frac{f_{i t}-\omega_{f, i t}}{\tau_{f}}\right)-\ln \tau_{f}\right]^{I_{f, i t}\left(1-I_{d, i t}\right)} } \\
+ & {\left[\ln \Phi_{2}\left(-\frac{\omega_{f, i t}}{\tau_{f}},-\frac{\omega_{d, i t}}{\tau_{d}}, \rho_{v}\right)\right]^{\left(1-I_{f, i t}\right)\left(1-I_{d, i t}\right)} }
\end{aligned}
$$


where

$$
\begin{aligned}
\omega_{f, i t} & :=\gamma_{0 f}^{\prime} x_{0, i t}+\gamma_{f f}^{\prime} x_{f, i t}+\gamma_{d f}^{\prime} x_{d, i t}+\delta_{0 f} \bar{x}_{0, i}+\delta_{f f} \bar{x}_{f, i}+\delta_{d f} \bar{x}_{d, i} \\
\omega_{d, i t} & :=\gamma_{0 d}^{\prime} x_{0, i t}+\gamma_{f d}^{\prime} x_{f, i t}+\gamma_{d d}^{\prime} x_{d, i t}+\delta_{0 d} \bar{x}_{0, i}+\delta_{f d} \bar{x}_{f, i}+\delta_{d d} \bar{x}_{d, i} \\
\tau_{f} & :=e^{\alpha_{f}+\eta J(n)} \\
\tau_{d} & :=e^{\alpha_{d}+\eta J(n)} \\
I_{f, i t} & :=1\left\{f_{i t}>0\right\} \\
I_{d, i t} & :=1\left\{d_{i t}>0\right\} .
\end{aligned}
$$

Optimisation of this log-likelihood function over $\theta_{0}=\left(\gamma_{0 f}, \gamma_{f f}, \gamma_{d f}, \gamma_{0 d}, \gamma_{f d}\right.$, $\left.\gamma_{d d}, \alpha_{f}, \alpha_{d}, \eta, \rho_{v}\right)$. produces consistent parameter estimates.

In the second step we make use of exclusion restrictions to identify the parameters $\lambda$ and $\mu$. Looking at (6), it can be easily seen that $\beta_{f}$ needs to have at least one element in order to identify $\lambda$. The same reasoning holds for $\beta_{d}$ and $\mu$. Thus, the fact that we are able to make use of variables exclusively affecting one of the two enrolment rates allows us to identify the level of substitution. In the next section we will further discuss the variables on which exclusion restrictions are imposed. For a more extensive discussion of this identification strategy the reader is referred to Koning \& van Vuuren (2006).

Now let us rewrite the restrictions shown in equation (6) as $g(\theta)=\theta_{0}$. Note that these equations do not include any restrictions on the heteroscedasticity parameter $\eta$, which means that we implicitly assume that the heteroscedastic component in $\tau_{f}$ and $\tau_{d}$ defined in (7) carries over to the error terms in the original model in (4c). Now, Minimum Distance estimation 
of $\theta$ is equivalent to minimising

$$
\Psi(\theta)=\left[\hat{\theta}_{0}-g(\theta)\right] \hat{\Sigma}_{v}^{-1}\left[\hat{\theta}_{0}-g(\theta)\right]^{\prime},
$$

where $\hat{\theta}_{0}$ is the maximum likelihood estimate of the reduced form model based on (10), and $\hat{\Sigma}_{v}^{-1}$ is the associated covariance matrix. The resulting parameter estimates $\hat{\theta}$ are consistent and asymptotically normally distributed with covariance matrix

$$
\hat{C}=\left[\hat{\Gamma}^{\prime} \hat{\Sigma}_{v}^{-1} \hat{\Gamma}\right]^{-1}
$$

where $\hat{\Gamma}=\left[\frac{\partial g(\theta)}{\partial \theta^{\prime}}\right]_{\theta=\hat{\theta}}$ (Chamberlain 1984). Minimisation of 11) takes place using the same routines as regular Maximimum Likelihood estimation. The likelihood is then defined as $-\Psi(\theta)$, and the number of observations and the number of parameters equal $\operatorname{dim}\left(\theta_{0}\right)$ and $\operatorname{dim}(\theta)$, respectively.

\section{Estimation results}

\subsection{Reduced form parameters}

Maximum Likelihood estimation results for the reduced form model (8) are shown in Table 2. Apart from firm size, year, and workforce composition variables, we have also included time averaged variables per collective labour agreement in order to control for unobserved heterogeneity. Looking at the coefficient estimates, firm size appears to be an important determinant both of UI and DI enrolment. The concerning dummy variables show a monotonic pattern, with large firms facing higher enrolment rates into both schemes than small firms. As expected, firm size also affects the variability of enrolment rates $(\eta)$, with small firms facing more variability than large 
firms. This variability however decreases less quickly for larger firms than would be expected on grounds of the law of large numbers, implying that either large firms have relatively volatile enrolment rates or large firms are more heterogeneous than small firms. Furthermore, it is found that firms with relatively few females in their ranks face higher UI enrolment rates. On the other hand, the DI enrolment rate does not seem to be affected by the gender composition of the firm's workforce.

Firms with relatively many elderly workers face lower UI and DI enrolment. UI enrolment is lower in firms with relatively many workers over age 50, and for DI enrolment this holds for firms with relatively many workers over age 60. A probable reason for this finding is that official early retirement schemes act as substitutes for UI and DI (Woittiez, Lindeboom \& Theeuwes 1994, Kerkhofs, Lindeboom \& Theeuwes 1999). Furthermore, a positive effect on DI enrolment is found for firms with relatively many workers in the ages between 30 and 60 . We may thus conclude that firms with relatively many young workers (under age 30) and old workers (over age 60) face lower DI enrolment rates than other firms.

Firms with a large share of part-time workers working less than 20 hours per week have significantly higher enrolment rates in both schemes. However, we were not able to include time-averages of these variables due to limited variation over time, so that selection effects may play a role (i.e. unhealthy workers select themselves into part-time jobs). The same applies for the educational composition: the higher educated probably prefer less risky jobs in terms of becoming disabled. Thus, the negative signs found for a higher educated workforce with respect to DI enrolment does not necessarily imply a lower risk of this group. 
[insert Table 2 about here]

\subsection{Structural parameters}

As was considered in the previous section, the estimation results just discussed can be used to obtain estimates of structural parameters by means of Minimum Distance estimation (MDE). To this end, we have to impose at least two exclusion restrictions. That is, we should have at least one instrumental variable affecting DI enrolment but not UI enrolment, and at least one instrumental variable affecting UI enrolment but not DI enrolment. (This is easily observed from equation (6): if $\gamma_{f f}, \gamma_{d f}, \gamma_{f d}$, and $\gamma_{d d}$ would be zero, then $\lambda$ and $\mu$ could not be identified.) Our exclusion restrictions therefore demand that no direct causal relation exists between the instrumental variables and the concerning enrolment rates. If there might exist some spurious correlation then this is no problem, because we correct both for observed and unobserved heterogeneity. The latter occurs through the inclusion of time averaged variables in the model (cf. equation (9)). Our first exclusion restriction is in line with Koning \& van Vuuren (2006), and assumes the wage distribution of the firms' employees not to affect their disability risk. The rationale behind this exclusion restriction is that the layoff decision of a firm is influenced by the wage level of its employees, in particular its relation to the productivity level. On the other hand, the 'health shock' leading to disability does not reasonably depend on the wage level of employees. Therefore, the finding in Table 2 that higher wages imply a higher incidence of DI enrolment is an indication of hidden unemployment.

Additionally, we postulate that function complexity exclusively affects disability risk. For instance, it could be expected that workers with relatively simple duties have a higher risk of becoming disabled. On the other hand, 
there is no reason to expect that the risk of unemployment is modified at different function complexity levels, given that the education level, the wage distribution, and other relevant factors are controlled for.

The results of the MDE routine are shown in Table 3. It is observed that the coefficients other than those used for identifying the structural parameters remain largely unaffected by the MDE routine, so that the discussion of the previous subsection still applies here. The correlation between the 'true' layoff and disability rate $\left(\rho_{f d}\right)$ could not be identified within the estimation routine, and was found using a grid search. As can be read from the table, the optimal value for this variable equals 0 , indicating that all correlation found between DI and UI can be explained by substitution effects. That is, no 'natural correlation' between UI and DI is found. Turning to the estimates of the structural parameters we are mostly interested in, we observe that a fraction of $3 \%$ of all desired dismissals is through the DI scheme $(\lambda)$. On the one hand this may look like a low figure, but then it should be taken into account that enrolment rates in UI are usually higher than in DI. Thus, if we apply equation (2b), it is seen that the figure of $3 \%$ translates into a share of hidden unemployment in DI enrolment of $26 \%$. On the contrary, we find no evidence for hidden disability in the unemployment scheme $(\mu)$. Hence, based on our point estimates the conclusion is that about a quarter of DI inflow is in fact hidden unemployment, while there is no evidence for reverse substitution. It is however noted that our point estimate for $\lambda$ is surrounded by quite a wide confidence interval.

[insert Table 3 about here] 


\section{Concluding remarks}

In this paper, we presented a model framework which allows us to estimate the amount of substitution between Disability Insurance (DI) and Unemployment Insurance (UI). In this model, a firm may either dismiss its employees through the UI scheme and/or lose some of its workers through the DI scheme, while allowing for substitution between both schemes in both directions. More specifically, a fraction of the desired dismissals may take place through the DI scheme, and a fraction of the disabled workers may end up in the UI scheme. The identification of these two respective fractions follows by the imposition of exclusion restrictions on certain variables, i.e. we assume these variables to affect one enrolment rate but not the other. In this paper we assumed that the firm's wage distribution exclusively affects UI enrolment, as their is no obvious explanation for health shocks to be correlated with wages, given that we correct for both firm and worker (observed and unobserved) heterogeneity. Note that Koning \& van Vuuren (2006) have checked the robustness of this exclusion restriction by comparing outcomes with other plausible exclusion restrictions, and found no substantial differences between the alternative sets of instrumental variables. Our second exclusion restriction demands that function complexity should not affect the firm's UI enrolment rate given that we control for firm heterogeneity.

Using the approach just outlined, we have estimated the degree of substitution between DI and UI in the Netherlands for the period 1993-2002. To this end, we employed an administrative data set of the Netherlands' Labour Inspectorate. Our estimation results indicate that about $3 \%$ of firms' layoffs take place through the DI scheme, which implies that about one quarter 
of the DI enrolments observed in our sample was in fact hidden unemployment. This figure is low compared to the earlier estimates of Aarts \& de Jong (1992) and Westerhout (1996), but somewhat higher than that of Hassink et al. (1997). Anyhow, our point estimates suggest that hidden unemployment in DI was still relevant during the 1990s and early 2000s. Our data have however not allowed us to perform estimations for separate years, so as to uncover any time pattern in this level of hidden unemployment. Using an alternative dataset, Koning \& van Vuuren (2006) managed to do this, and found that the level of hidden unemployment in DI has substantially decreased over the years.

The large number of policy measures taken during the 1990s were to a large extent meant to reduce erroneous admissions (or type II errors) into DI. However, as is known from statistical theory, the reduction of type II errors implies a greater risk of making type I errors, i.e. erroneous denials. In this study we did however not find any evidence for hidden disability in UI. Note that with respect to the 2002 reform (see section 2) a similar finding was established in de Jong et al. (2006): the reform proved effective in terms of reducing DI inflow but no additional UI inflow was found.

\section{Acknowledgments}

The authors thank Rob Euwals, Peter Kooiman, Aico van Vuuren, Adriaan Kalwij, and Peter Rijnsburger for useful comments and discussions, and Ali Aouragh and Janneke Rijn for research assistance. 


\section{References}

Aarts, L. \& de Jong, P. (1992), Economic Aspects of Disability Behaviour, North-Holland, Amsterdam.

Autor, D. \& Duggan, M. (2003), 'The rise in the disability rolls and the decline in unemployment', Quarterly Journal of Economics 118, 157205.

Black, D., Daniel, K. \& Sanders, S. (2002), 'The impact of the economic conditions on participation in disability programs: Evidence from the coal boom and bust', American Economic Review 92, 27-50.

Chamberlain, G. (1984), Panel data, in Z. Griliches \& M. Intriligator, eds, 'Handbook of Econometrics', Vol. 2, North-Holland, chapter 22, pp. $1247-1318$.

de Jong, P., Lindeboom, M. \& van der Klaauw, B. (2006), Screening Disability Insurance Applications. mimeo.

Duggan, M., Singleton, P. \& Song, J. (2005), Aching to retire? The rise in the full retirement age and its impact on the disability rolls, NBER Working Paper 11811, NBER.

Euwals, R., van Vuuren, D. \& Wolthoff, R. (2006), Early retirement behaviour in the Netherlands. Evidence from a policy reform, CEPR Discussion Paper 5596, CEPR.

Gruber, J. (2000), 'Disability insurance benefits and labour supply', Journal of Political Economy 108, 1162-1183.

Hassink, W. (2000), 'Job destruction through quits or layoffs?', Applied Economics Letters 7, 45-47. 
Hassink, W., van Ours, J. \& Ridder, G. (1997), 'Dismissal through disability', De Economist 145(1), 29-46.

Kerkhofs, M., Lindeboom, M. \& Theeuwes, J. (1999), 'Retirement, financial incentives and health', Labour Economics 6, 203-227.

Koning, P. \& van Vuuren, D. (2006), Hidden Unemployment in Disability Insurance in the Netherlands; An Empirical Analysis Based on Employer Data, CPB Discussion Paper 69, CPB Netherlands Bureau for Economic Policy Analysis.

Riphahn, R. (1997), 'Disability retirement and unemployment - substitute pathways for labour exit? an empirical test for the case of Germany', Applied Economics 29, 551-561.

Westerhout, E. (1996), 'Hidden unemployment in Dutch disability schemes', CPB Report 2, 24-29.

Woittiez, I., Lindeboom, M. \& Theeuwes, J. (1994), Labour Force Exit Routes of the Dutch Elderly: A Discrete Choice Model, in L. Bovenberg, ed., 'The Economics of Pensions: The Case of the Netherlands', Rotterdam: Ocfeb.

Wooldridge, J. (2002), Econometric Analysis of Cross Section and Panel Data, MIT Press. 


\section{Tables and figures}

Figure 1: Yearly DI and UI enrolment rates (source: UWV, CBS, own calculations)

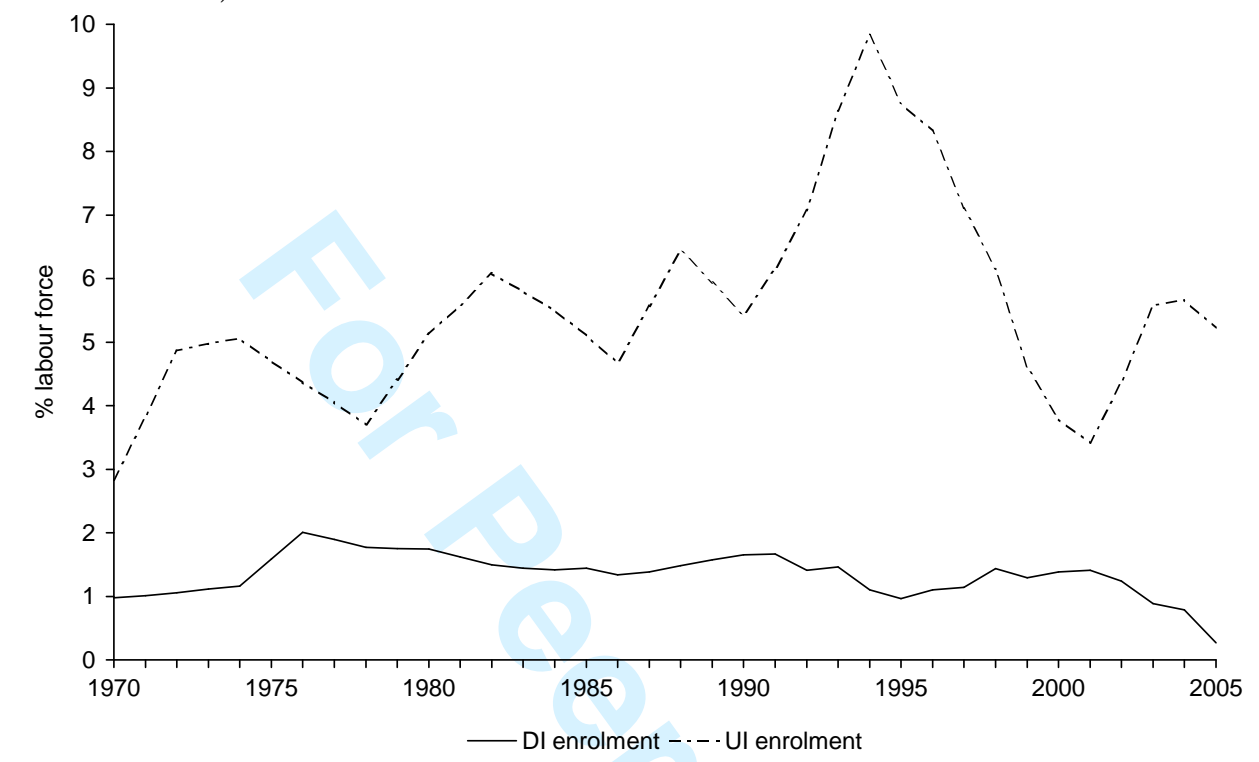


Figure 2: DI and UI recipients (source: UWV, CBS, own calculations)

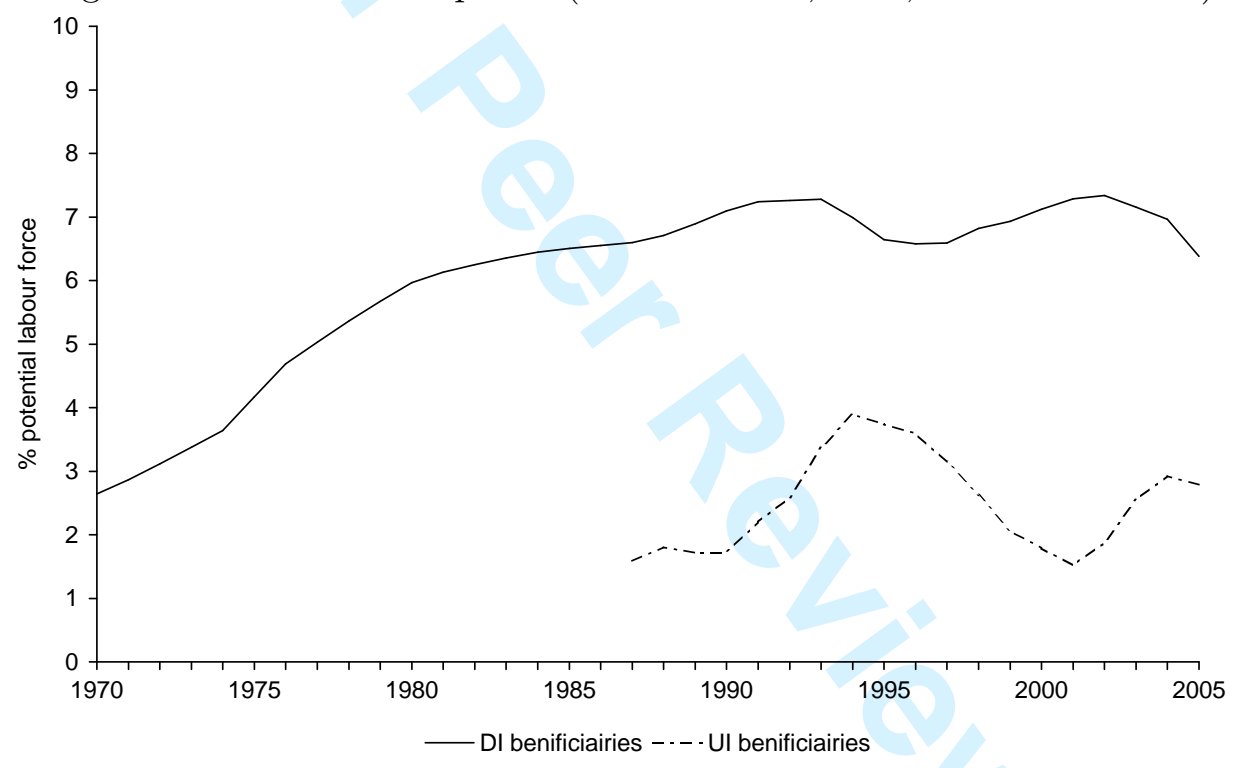


Table 1: Sample statistics AVO-data set, $n=10437$

\begin{tabular}{lrrrr}
\hline & Mean & Std.dev. & Minimum & Maximum \\
\hline UI enrolment & $3.4 \%$ & $7.6 \%$ & $0 \%$ & $100 \%$ \\
DI enrolment & $0.4 \%$ & $1.9 \%$ & $0 \%$ & $50 \%$ \\
UI enr. = 0; DI enr. =0 & $96.2 \%$ & & & \\
UI enr. > 0; DI enr. =0 & $3.4 \%$ & & & \\
UI enr. = 0; DI enr. > 0 & $0.4 \%$ & & & \\
UI enr. > 0; DI enr. > 0 & $0.0 \%$ & & \\
$\rho($ UI enr. , DI enr. ) & -0.023 & & \\
$" \quad$ in 1993 & -0.011 & & \\
$" \quad$ in 1994 & 0.180 & & \\
$" \quad$ in 1995 & -0.009 & & \\
$" \quad$ in 1997 & -0.011 & & & \\
$" \quad$ in 1998 & -0.039 & & & \\
$" \quad$ in 2000 & -0.022 & & & \\
$" \quad$ in 2001 & in 2002 & -0.051 & &
\end{tabular}

Workforce composition

Age

$15-29$

30-39

0.35

0.27

0.19

0.28

0.18

$40-49$

0.22

0.15

0.13

0.05

$\begin{array}{ll}0 & 1 \\ 0 & 1 \\ 0 & 1 \\ 0 & 1 \\ 0 & 1\end{array}$

$>=60$

0.01

0.33

0

1

Female

0.36

0.18

$\begin{array}{ll}0 & 1\end{array}$

Primary

0.08

0.18
0.32

0.59

0.32
0.25

Upper secondary

0.25

Tertiary

0.09

0.16

$0 \quad 1$

Part-time work

$\begin{array}{llll}0.30 & 0.25 & 0 & 1\end{array}$

less than 20 hours

0.09

0.15

0.61

0.30

0

1

32 hours or more

6.37

2.53

0

1

Income (Ln)

$8.01 \quad 0.61$

9.22

Third Quartile

9.75

a The logarithmic transformation is used for variables related to income. 
Table 1: Sample statistics AVO-data set (continued)

\begin{tabular}{|c|c|c|c|c|}
\hline & Mean & Std.dev. & Minimum & Maximum \\
\hline \multicolumn{5}{|c|}{ Workforce composition (continued) } \\
\hline \multicolumn{5}{|c|}{ Function type } \\
\hline \multicolumn{5}{|l|}{$\begin{array}{l}\text { Production, technical, } \\
\text { manual labour }\end{array}$} \\
\hline Administrative & 0.11 & 0.16 & 0 & 1 \\
\hline Automation & 0.01 & 0.04 & 0 & 1 \\
\hline Commercial & 0.13 & 0.27 & 0 & 1 \\
\hline Care, service & 0.29 & 0.37 & 0 & 1 \\
\hline Creative & 0.01 & 0.07 & 0 & 1 \\
\hline Managerial & 0.06 & 0.08 & 0 & 1 \\
\hline \multicolumn{5}{|l|}{ Function complexity } \\
\hline Very basic & 0.06 & 0.16 & 0 & 1 \\
\hline Basic & 0.20 & 0.28 & 0 & 1 \\
\hline Less basic & 0.41 & 0.33 & 0 & 1 \\
\hline Difficult & 0.24 & 0.26 & 0 & 1 \\
\hline Complex & 0.08 & 0.14 & 0 & 1 \\
\hline Lower executive & 0.02 & 0.06 & 0 & 1 \\
\hline Middle executive & 0.00 & 0.01 & 0 & 0.36 \\
\hline \multicolumn{5}{|l|}{ Firm size } \\
\hline 1-4 employees & 0.21 & 0.41 & 0 & 1 \\
\hline 5-9 employees & 0.18 & 0.38 & 0 & 1 \\
\hline 10-19 employees & 0.16 & 0.37 & 0 & 1 \\
\hline 20-49 employees & 0.15 & 0.35 & 0 & 1 \\
\hline 50-99 employees & 0.10 & 0.30 & 0 & 1 \\
\hline 100-199 employees & 0.08 & 0.27 & 0 & 1 \\
\hline 200-499 employees & 0.08 & 0.27 & 0 & 1 \\
\hline 500 employees or more & 0.05 & 0.22 & 0 & 8 \\
\hline \multicolumn{5}{|l|}{ Year Dummies } \\
\hline 1993 & 0.12 & 0.33 & 0 & 1 \\
\hline 1994 & 0.13 & 0.34 & 0 & 1 \\
\hline 1995 & 0.11 & 0.32 & 0 & 1 \\
\hline 1997 & 0.12 & 0.32 & 0 & 1 \\
\hline 1998 & 0.12 & 0.32 & 0 & 1 \\
\hline 2000 & 0.12 & 0.32 & 0 & 1 \\
\hline 2001 & 0.16 & 0.36 & 0 & 1 \\
\hline 2002 & 0.12 & 0.32 & 0 & 1 \\
\hline
\end{tabular}


Table 2: Estimation results for whole sample (1993-2002): reduced form parameters of Bivariate Tobit model for UI and DI enrolment

\begin{tabular}{lrrrr} 
& UI enrolment & \multicolumn{3}{c}{ DI enrolment } \\
& Coefficient & St.error & Coefficient & St.error \\
\hline Age 30-39 & 0.002 & 0.011 & 0.039 & 0.013 \\
Age 40-49 & -0.012 & 0.012 & 0.050 & 0.013 \\
Age 50-59 & -0.057 & 0.014 & 0.055 & 0.015 \\
Age $\geq 60$ & -0.188 & 0.049 & -0.037 & 0.053 \\
Female & -0.038 & 0.011 & -0.004 & 0.011 \\
Lower secondary & -0.001 & 0.011 & -0.035 & 0.009 \\
Upper secondary & -0.011 & 0.013 & -0.041 & 0.011 \\
Tertiary & -0.006 & 0.017 & -0.047 & 0.015 \\
Less than 20 hours & 0.077 & 0.014 & 0.058 & 0.017 \\
20-32 hours & -0.009 & 0.016 & 0.009 & 0.018 \\
First Quartile ln(wage) & -0.015 & 0.001 & -0.002 & 0.001 \\
Third Quartile ln(wage) & 0.018 & 0.003 & 0.021 & 0.007 \\
Administrative & 0.013 & 0.011 & -0.030 & 0.013 \\
Automation & -0.034 & 0.046 & -0.049 & 0.041 \\
Commercial & -0.015 & 0.009 & -0.008 & 0.009 \\
Care, service & 0.014 & 0.006 & -0.008 & 0.006 \\
Creative & -0.035 & 0.023 & -0.015 & 0.026 \\
Managerial & 0.038 & 0.023 & 0.066 & 0.022 \\
Basic & 0.042 & 0.014 & -0.008 & 0.015 \\
Less basic & 0.040 & 0.014 & -0.007 & 0.014 \\
Difficult & 0.056 & 0.015 & 0.000 & 0.016 \\
Complex & 0.082 & 0.020 & -0.027 & 0.021 \\
Lower executive & 0.127 & 0.037 & -0.045 & 0.034 \\
Middle executive & -0.010 & 0.125 & -0.087 & 0.120 \\
5-9 employees & 0.040 & 0.009 & 0.052 & 0.010 \\
10-19 employees & 0.076 & 0.009 & 0.091 & 0.010 \\
20-49 employees & 0.110 & 0.009 & 0.126 & 0.010 \\
50-99 employees & 0.139 & 0.009 & 0.175 & 0.010 \\
100-199 employees & 0.152 & 0.008 & 0.190 & 0.011 \\
200-499 employees & 0.164 & 0.008 & 0.200 & 0.011 \\
$\geq 500$ employees & 0.145 & 0.008 & 0.210 & 0.011 \\
Year = 1994 & -0.149 & 0.009 & -0.006 & 0.006 \\
Year = 1995 & -0.154 & 0.010 & -0.019 & 0.007 \\
Year = 1997 & 0.026 & 0.006 & -0.012 & 0.007 \\
Year = 1998 & 0.028 & 0.006 & -0.014 & 0.006 \\
Year = 2000 & 0.003 & 0.006 & -0.012 & 0.007 \\
Year = 2001 & 0.006 & -0.015 & 0.006 \\
Year = 2002 & 0.007 & -0.001 & 0.007 \\
\hline & & &
\end{tabular}


Table 2: Estimation results for whole sample (1993-2002): reduced form parameters of Bivariate Tobit model for UI and DI enrolment (continued)

\begin{tabular}{lrrrr}
\hline & UI enrolment & \multicolumn{3}{c}{ DI enrolment } \\
& Coefficient & St.error & Coefficient & St.error \\
\hline Time averages & & & & \\
Age 30-39 & 0.089 & 0.043 & 0.155 & 0.033 \\
Age 40-49 & 0.036 & 0.035 & 0.125 & 0.033 \\
Age 50-59 & 0.083 & 0.039 & 0.016 & 0.041 \\
Age $\geq 60$ & -0.170 & 0.139 & 0.194 & 0.119 \\
Female & 0.018 & 0.013 & 0.000 & 0.013 \\
First Quartile ln(wage) & 0.015 & 0.002 & 0.012 & 0.003 \\
Third Quartile ln(wage) & 0.002 & 0.010 & -0.010 & 0.012 \\
Basic & 0.010 & 0.032 & 0.084 & 0.031 \\
Less basic & 0.005 & 0.026 & 0.024 & 0.024 \\
Difficult & -0.028 & 0.029 & 0.002 & 0.027 \\
Complex & -0.040 & 0.036 & 0.017 & 0.036 \\
Lower executive & -0.108 & 0.065 & -0.002 & 0.071 \\
Middle executive & -0.114 & 0.268 & 0.128 & 0.225 \\
Other model parameters & & & & \\
Constant & -0.457 & 0.083 & -0.503 & 0.091 \\
$\tau_{f}$ & 0.204 & 0.004 & & \\
$\tau_{d}$ & 0.150 & 0.004 & & \\
$\rho_{v}$ & 0.015 & 0.029 & & \\
$\eta$ & -0.171 & 0.003 & & \\
\hline
\end{tabular}


Table 3: Estimation results for whole sample (1993-2002): structural parameters of Bivariate Tobit model for UI and DI enrolment

\begin{tabular}{|c|c|c|c|c|}
\hline & \multicolumn{2}{|l|}{ UI enrolment } & \multicolumn{2}{|c|}{ DI enrolment } \\
\hline & Coefficient & St.error & Coefficient & St.error \\
\hline Age $30-39$ & 0.010 & 0.012 & 0.048 & 0.014 \\
\hline Age $40-49$ & -0.006 & 0.013 & 0.050 & 0.013 \\
\hline Age 50-59 & -0.054 & 0.014 & 0.063 & 0.016 \\
\hline Age $\geq 60$ & -0.191 & 0.052 & -0.034 & 0.056 \\
\hline Female & -0.044 & 0.011 & -0.009 & 0.012 \\
\hline Lower secondary & 0.007 & 0.011 & -0.036 & 0.010 \\
\hline Upper secondary & 0.002 & 0.013 & -0.040 & 0.011 \\
\hline Tertiary & 0.025 & 0.016 & -0.046 & 0.015 \\
\hline less than 20 hours & 0.073 & 0.016 & 0.041 & 0.017 \\
\hline 20-32 hours & -0.015 & 0.017 & 0.008 & 0.018 \\
\hline First Quartile $\ln$ (wage) & -0.016 & 0.001 & & \\
\hline Third Quartile $\ln$ (wage) & 0.019 & 0.003 & & \\
\hline Administrative & 0.016 & 0.012 & -0.029 & 0.013 \\
\hline Automation & -0.029 & 0.047 & -0.048 & 0.041 \\
\hline Commercial & -0.011 & 0.009 & -0.007 & 0.009 \\
\hline Care, service & 0.016 & 0.007 & -0.009 & 0.006 \\
\hline Creative & -0.035 & 0.023 & 0.001 & 0.026 \\
\hline Managerial & 0.063 & 0.024 & 0.073 & 0.024 \\
\hline Basic & & & 0.053 & 0.030 \\
\hline Less basic & & & 0.047 & 0.022 \\
\hline Difficult & & & 0.028 & 0.025 \\
\hline Complex & & & 0.019 & 0.032 \\
\hline Lower executive & & & -0.007 & 0.055 \\
\hline Middle executive & & & -0.216 & 0.231 \\
\hline 5-9 employees & 0.041 & 0.011 & 0.053 & 0.012 \\
\hline 10-19 employees & 0.080 & 0.015 & 0.091 & 0.016 \\
\hline 20-49 employees & 0.114 & 0.018 & 0.126 & 0.020 \\
\hline 50-99 employees & 0.145 & 0.024 & 0.174 & 0.025 \\
\hline 100-199 employees & 0.158 & 0.025 & 0.190 & 0.027 \\
\hline 200-499 employees & 0.173 & 0.026 & 0.198 & 0.028 \\
\hline$\geq 500$ employees & 0.152 & 0.026 & 0.209 & 0.028 \\
\hline Year = 1994 & -0.159 & 0.012 & -0.002 & 0.010 \\
\hline Year $=1995$ & -0.160 & 0.013 & -0.015 & 0.011 \\
\hline Year $=1997$ & 0.027 & 0.006 & -0.012 & 0.007 \\
\hline Year $=1998$ & 0.029 & 0.007 & -0.014 & 0.006 \\
\hline Year $=2000$ & -0.002 & 0.006 & -0.010 & 0.007 \\
\hline Year $=2001$ & 0.162 & 0.010 & -0.014 & 0.010 \\
\hline Year $=2002$ & 0.146 & 0.010 & -0.016 & 0.009 \\
\hline
\end{tabular}


Table 3: Estimation results for whole sample (1993-2002): structural parameters of Bivariate Tobit model for UI and DI enrolment (continued)

\begin{tabular}{lrrrr}
\hline & UI enrolment & \multicolumn{3}{c}{ DI enrolment } \\
& Coefficient & St.error & Coefficient & St.error \\
\hline Time averages & & & & \\
Age 30-39 & 0.076 & 0.047 & 0.150 & 0.036 \\
Age 40-49 & 0.035 & 0.038 & 0.136 & 0.037 \\
Age 50-59 & 0.077 & 0.041 & -0.004 & 0.041 \\
Age $\geq 60$ & -0.178 & 0.144 & 0.235 & 0.120 \\
Female & 0.019 & 0.013 & 0.008 & 0.013 \\
First Quartile ln(wage) & 0.016 & 0.002 & 0.010 & 0.003 \\
Third Quartile ln(wage) & -0.002 & 0.010 & 0.002 & 0.012 \\
Basic & 0.053 & 0.030 & 0.083 & 0.032 \\
Less basic & 0.047 & 0.022 & 0.023 & 0.024 \\
Difficult & 0.028 & 0.025 & 0.004 & 0.027 \\
Complex & 0.019 & 0.032 & 0.010 & 0.036 \\
Lower executive & -0.007 & 0.055 & -0.005 & 0.070 \\
Middle executive & -0.216 & 0.231 & 0.151 & 0.223 \\
Other model parameters & & & & \\
Constant & -0.441 & 0.103 & -0.431 & 0.107 \\
$\sigma_{f}$ & 0.211 & 0.011 & & \\
$\sigma_{d}$ & 0.153 & 0.012 & & \\
$\rho_{f d}$ & 0.000 & - & & \\
$\lambda$ & 0.030 & 0.049 & & \\
$\mu$ & 0.000 & 0.085 & & \\
\hline
\end{tabular}

